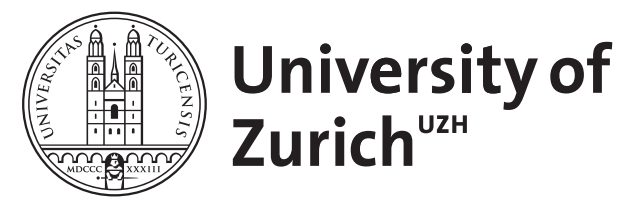

\title{
Happiness and altruism within the extended family
}

\author{
Schwarze, Johannes ; Winkelmann, Rainer
}

\begin{abstract}
We propose a direct measure of altruism between parents and adult children, using survey data on happiness from the German Socio-Economic Panel for the years 2000-2004. The question of altruism within families has policy relevance, for example, to understand whether public transfers crowd out private ones. Previous empirical evidence, based on observed transfer behavior, has failed to establish a clear consensus. Using various cross section, panel data, and instrumental variable estimators, we find a robust association between the happiness of parents and that of their adult children. A 1 standard deviation increase in a child's happiness is associated with the same increase in own happiness as that of a $20-45 \%$ increase in household income, depending on specification.
\end{abstract}

DOI: https://doi.org/10.1007/s00148-010-0326-8

Posted at the Zurich Open Repository and Archive, University of Zurich

ZORA URL: https://doi.org/10.5167/uzh-50625

Journal Article

Accepted Version

Originally published at:

Schwarze, Johannes; Winkelmann, Rainer (2011). Happiness and altruism within the extended family. Journal of Population Economics, 24(3):1033-1051.

DOI: https://doi.org/10.1007/s00148-010-0326-8 


\title{
Happiness and altruism within the extended family*
}

\author{
JoHANNES SCHWARZE \\ University of Bamberg and IZA
}

\author{
RAINER WINKELMANN \\ University of Zurich and IZA
}

May 2010

\begin{abstract}
We propose a direct measure of altruism between parents and adult children, using survey data on happiness from the German Socio-Economic Panel for the years 2000-2004. The question of altruism within families has policy relevance, for example to understand whether public transfers crowd out private ones. Previous empirical evidence, based on observed transfer behavior, has failed to establish a clear consensus. Using various cross-section, panel data and instrumental variable estimators, we find a robust association between the happiness of parents and that of their adult children. A one standard deviation increase in a child's happiness is associated with the same increase in own happiness as that of a 20-45 percent increase in household income, depending on specification.
\end{abstract}

JEL Classification: D6, D64, C25, J10

Keywords: utility interdependence, sympathy, extended family, fixed effects

*Address for correspondence: University of Zurich, Socioeconomic Institute, Zürichbergstr. 14, CH-8032 Zürich, Switzerland; email: johannes.schwarze@sowi.uni-bamberg.de, winkelmann@sts.uzh.ch. An earlier version of the paper was presented at seminars in Berlin, Gottlieben, Lausanne, Philadelphia, and at the 2005 population economics meeting of the German Economic Association in Basel. We thank Guido Heineck, Rafael Lalive, Gert Wagner, Liliana Winkelmann, Joachim Wolff, Christoph Wunder, as well as two anonymous referees for helpful comments. The data used in this paper were made available by the German Socio Economic Panel Study (GSOEP) at the German Institute for Economic Research (DIW), Berlin. 
"How selfish soever man may be supposed, there are evidently some principles in his nature, which interest him in the fortune of others, and render their happiness necessary to him, though he derives nothing from it except the pleasure of seeing it."

Adam Smith (1790)

"...we might suppose that the object which $X$ (whose own utility is $P$ ) tends - in a calm, effective moment - to maximise, is not $P$ but $P+\lambda \Pi$; where $\lambda$ is a coefficient of effective sympathy."

Francis Ysidro Edgeworth (1881, p. 53)

\section{Introduction}

Altruism denotes the willingness to make voluntary transfer of resources to another person or other persons, disregarding of own benefit. The empirical importance of altruism for economics has been debated for several decades, yet no clear consensus has emerged so far. An initial literature was concerned with the way resources are distributed within the extended family, and its consequences for optimal public transfer policies (Becker, 1981, Altonji et al., 1992). More recently, evidence on widespread pro-social behavior in laboratory experiments has led to renewed interest in altruism and challenged the view that economic agents mostly behave selfishly (Fehr and Fischbacher, 2003). Importantly, altruistic behavior is found not only among related family members but also among strangers in one-shot interactions.

Behavior-based research of altruism faces the obstacle that such transfers can almost always be attributed to a number of different motives. If the motive for a transfer is "nothing except the pleasure of seeing the happiness of others", as Adam Smith puts it, than we have indeed an instance of genuine altruism. But other motives reflect plain selfishness, because they give the donor a personal benefit. Among the possible benefits are "joy-of-giving" or "warm glow" effects (Andreoni, 1990), whereby the act of giving provides a source of satisfaction per-se, for example by according prestige or respect to 
the donor, a benefit that is independent of how the beneficiary values the transfer. Another potential benefit is reciprocity, i.e. the expectation that a favor is returned in future. Also, pro-social behavior can lead to positive reputation effects that eventually provide material benefits.

While the literature has proposed a number of tests between these alternative explanations, some based on observational data, others on laboratory experiments (e.g. Altonji et al., 1992, Ribar and Wilhelm, 2002, Fehr and Fischbacher, 2003), we suggest in this paper an alternative route for uncovering genuine altruism, namely by exploiting information on measured utility of people. Such information can reveal the extent to which preferences are other-regarding, or interdependent. Interdependent preferences, in turn, can be seen as the proximate mechanism by which genuinely altruistic behavior is induced in humans. In other words, without interdependent preferences, all observed behaviors of apparently altruistic transfers would need to be ascribed to selfish motives.

In this sense, interdependent preferences are more fundamental to altruism than actual transfers: the absence of transfers (or altruistic behavior more broadly defined) in a specific period and environment does not rule out altruism in general, while the absence of interdependent preferences does. For the former, consider the situation of parents and their children: if income flows are very similar, altruistic parents will nott make transfers although they would do so if a sufficiently large income gap were to develop.

The approach we propose is based on self-reported happiness as a proxy for utility. We analyze the extent of interdependent preferences in the context of parents and their adult children who have moved out and live on their own. The objective of the paper is thus to test whether, and to what extent, parents' happiness is related to that of their children. For that purpose, a unique linked parent-child dataset has been extracted from the German Socio-Economic Panel for the years 2000 to 2004 .

Our primary finding is that of a strong association between the utility proxies, i.e. evidence for interdependent preferences. We explore a number of potential explanations, including shared environment, inherited predisposition towards happiness, paternalistic preferences and reversed causation. The 
positive association persists after controlling for a host of socio-economic background variables and, exploiting the longitudinal structure of the data, individual specific time invariant fixed effects. We also performed instrumental variable estimation, although it is difficult to find credible instruments in the data, and the required exclusion restrictions may not hold for the instruments we used. While this leaves some uncertainty as to the magnitude of the association, we can reject the null hypothesis of no preference independence in all specifications. This robustness supports the view that parents' and child's happiness are indeed related, and that this relation can be measured in survey data. Depending on specification, a 1.5 point (one standard deviation) increase in child's happiness is associated with an increase in parents' reported happiness that equals that of a 20-45 percent increase in own income.

\section{Happiness and altruism}

Measures of happiness have been developed and tested extensively in psychological research (Diener, 1984). In the simplest case, there is a single item question on life-satisfaction, or happiness. According to Veenhoven, "happiness is the degree to which a person evaluates the overall quality of his present life-as-a-whole positively" (Veenhoven, 1997, p.3.) There is a general consensus that subjective wellbeing taps primarily into cognitive dimensions, to a large extent independently of affect (Diener et al., $1985)$.

These happiness data are increasingly used to tackle important questions in economics, as reviewed in Frey and Stutzer (2002), Layard (2005) and Di Tella and MacCulloch (2006). Indeed, the recent surge in interest is quite dramatic, as pointed out by Clark et al. (2008a), who counted 417 happiness related articles between 1960 and 2005 in Econlit. Of these, 76 percent had been published since 1995 and 30 percent since 2003. Most of these papers use, in one way or another, answers to current happiness or life satisfaction questions in cross-section and panel survey data to study the factors that determine wellbeing, among them economic policies and institutions. Some of them test whether happiness predicts behavior. Clark et al. (1998) show that low job satisfaction predicts quits; Clark et al. (2008b) show 
that low happiness among married people predicts divorce.

The majority of papers has taken an individualistic approach to happiness: one person's happiness is not directly affected by how happy others are. Instead, there has been a substantial amount of work on indirect interdependence, such as status interdependence or other kinds of externalities (e.g. Clark and Oswald, 1996). Where direct interdependence has been studied, it has been limited to happiness interdependence among individuals within the same household (e.g. Shields and Price, 2005, Winkelmann, 2005, Powdthavee, 2009).

In this paper, we broaden the scope of analysis and investigate interdependence among individuals living in separate households. Clearly, it is meaningless to search for interdependence between randomly selected households. The households must be somehow related, know each other, communicate and interact. In our case, the relationship is that of kinship, as we consider parent households and child households. Alternative relationships are possible. Fowler and Christakis (2008), for instance, analyze happiness interdependence among friends.

Our focus on the relationships between parents and children ties in with the economic literature on altruism within extended family. Becker (1981, 1991), taking seriously the Edgeworth (1881) proposal, formalized altruism within a framework of utility maximization under interdependent preferences. Formally, suppose that

$$
V_{p}=U_{p}+\eta U_{k}
$$

where the total utility of a parent $V_{p}$ is additively related to the child's utility $U_{k}$. In this very simple model, $\eta$ is the "coefficient of effective sympathy", to follow Edgeworth's definition, or, in our context, the altruism parameter. If $\eta$ is zero, we have a situation of non-interdependent preferences, or "selfishness". For positive $\eta$, an increase in the child's utility leads to an increase in the parent's utility. We call this situation one of "altruistic preferences". A negative $\eta$ would reflect envy.

Becker (1981) showed that utility function (1) implies altruistic behavior: under certain circumstances, parents will transfer resources to their children. But the inverse conclusion does not hold: 
transfers can have many motives, and knowing whether they are driven by altruism, exchange, or joy of giving is relevant for many policy questions, including efficient reform of old age security, long-term care and social assistance. It can be shown, e.g., that attempts by governments to redistribute income between generations can be neutralized if families are altruistic, since if the income of a beneficiary of an altruistic transfer is increased, that transfer will be reduced by an equal amount (see Laferrére and Wolff, 2006, for a recent survey of the literature).

The majority of empirical papers estimate inter household transfer equations where the amount of transfers from parents to children is regressed on the parents' income and income of the child together with other variables. Subsequently, tests can be set up to verify predictions from the model of altruistic families. However, this approach requires specific data on transfer payments between family members. As indicated by Altonji et al. (1992), the timing of transfers is arbitrary, so that studies that are not able to cover a long period may lead to incorrect conclusions. In addition, non-monetary transfers, such as services or household produced goods, are difficult to observe.

\section{Data}

Our empirical analysis is based on the 2000-2004 waves of the German Socio-Economic Panel (GSOEP). This panel household survey was started in 1984 with a random sample of 5,624 households in West Germany (Wagner, Burkhauser and Behringer, 1993). In 1990, it was augmented by a sample of East German households. From the outset, an attempt was made to trace and interview adult children who moved from their parents' household to live in an own household alone or together with a partner and own children. If the tracing was successful, the GSOEP allows to link the original household with its spin-off(s). It is therefore possible to merge data on parents with those on their children who have moved out. Initially, such cases were rare but in recent years the number of linkable parent-child observations became quite large, enabling the kind of analysis we want to conduct. We therefore selected the year 2000 as our first year of analysis. For that year, we could identify 930 parent households with linkable 
spin-offs. By 2004, that number had increased to 1,118 parent households.

The basic unit of observation is a parent-child pair. We started by extracting all parents. If we could find for any of these fathers or mothers in any year information on at least one child living in a spin-off household, this parent-child pair constitutes one observation. Each additional year for a given child, or each additional child in a given year, generates one additional observation. The cross-sectional structure of the dataset from the parents' point of view, for the year 2002, is depicted in Table 1 . There were 1,750 parents for whom information on up to five children not living in the same household was available. Information for exactly one adult child not living in the same household was present for 1,317 parents. 363 parents can be matched to two children, and so on. All together the 2002 data comprise 2,264 observations (=parent/child pairs). From the total of 1,750 parents, 1,454 or 83 percent are couples whereas the remaining 296 cases refer to single parents.

Table 1 about here

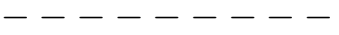

In the 2000-2004 time dimension, the data form an unbalanced panel. The number of parents (counting mothers and fathers separately) with at least one entry in any of the five years is 2,562. 26.4 percent of parents are observed at most three times, 19.6 percent are included four times and the remaining 54.0 percent is observed in all five years, adding up to 8,630 separate parent-year observations. The total number of adult and independently living children contributing at least one observation is 2,009. Again, many children are observed repeatedly over time, so that there is a total of 6,520 child-year observations.

The particular structure of the dataset deserves some comment, as it deviates from the standard random sampling assumption in a number of ways, necessitating corresponding adjustments to the econometric analysis. First, there are multiple observations for the same parent-child pair over time. Time invariant effects can be accounted for by using fixed effects, random effects, or by adjusting the 
standard errors for clustering.

Second, at any point in time, there can be either one or two parent-child observations in the same household. Two observations occur if both mothers and fathers respond in the survey. Household effects can be either period specific, or time invariant. In the latter case, since parents are nested within households, household fixed effects do not contribute anything over and above parent fixed effects mentioned previously. In the former case, it is not an option to condition on period specific household effects, since the main variable of interest, child happiness, does not vary between fathers and mothers at one point in time. Instead, standard errors can be adjusted for clustering at the household level.

Third, instances where the same parent is matched to several children constitute a problem in a regression context. The stochastic error capturing the unobserved determinants of a parents happiness is essentially the same, regardless of whether we condition on the happiness of a first, or that of a second child, and hence these observations cannot be independent. While this does not make running a regression technically impossible, one would need to account for the near perfect correlation when computing standard errors. Alternatively, one can average over the children's observations and run the regression using such synthetic parent-child pairs. This approach is chosen in this paper. It also ensures that parents with multiple children do not get stronger weights in the regression than parents with a single child. The sensitivity of the results to taking averages was explored by using alternative samples limited to parents with one child or the oldest child only, but none of the substantive conclusions was affected.

For each parent and child, we extracted a wide range of household and person specific socio-economic variables. Happiness is measured using the following question: "How satisfied are you with your life, all things considered? Please answer according to the following scale: "0" means completely dissatisfied, "10" means completely satisfied". Life satisfaction and happiness are treated here as synonymous. Potential determinants of happiness include: age, age squared, health, gender, nationality, years of education, marital status, whether widowed, whether divorced, household size, number of children, 
place of abode, employment status and income. Health is measured by a self rating of the respondents on a five point scale, and converted to a "good-health" indicator for the values four and five. Income is measured as disposable monthly post-government income of the household. Instead of applying an arbitrary equivalence scale, all models adopt a flexible specification of economies of scale by including the log of household size, in addition to the log of household income.

The following variables are extracted for adult children not living in the parent's household: age, gender, marital status, health, education, employment status and household income. They are computed in the same way as they were for parents. In Table 2 we see that the arithmetic mean of the happiness response is a 6.6 for parents and a 7.1 for children. Parents are on average about 26.7 years older than their adult children. Children report a substantially better health than parents (70 percent as opposed to 31 percent with "good health"). On the other hand, the marital rate is much lower among adult children than among parents (46 percent as opposed to 82 percent). Fewer adult children own a house, and their average log income is about $13 \log$ points below that of their parents.

Table 2 about here

We also observe, when children left their parental home and how far they moved. The average age at moving out is 23.3 years. Since the average age at the time of survey is 30.7 , it means that these children have lived on their own for an average of about 7 years. There is substantial variation in the time away. About 20 percent of all children have moved within the last 2 years; about 25 percent of all children have moved out more than ten years earlier. One might suspect that the elapsed time since moving out can affect the strength of measured preference interdependence, an interaction that will be tested.

A similar moderation might result from the distance between parent and child. For example, any happiness interdependence effectively requires that parents know about their children's momentary 
happiness, and distance can serve as a measure of the quality of that information. For example, the greater the distance between the households, the less accurately might parents be informed about the living conditions and well-being of their children. In addition, of course, distance itself might directly influence a parent's happiness.

We employ two measures for geographical distance (This part of research using regional information was carried out at the DIW Berlin. We thank the staff for making the information available.) A first is a simple indicator whether or not the child lives in the same district as the parents - this is the case for 65 percent of all children. The second is the distance in kilometers, using the geographical coordinate of the county of residence's midpoint (European Terrestrial Reference System, ETRS89). The average distance between a parent's household and a child's household amounts to 49 kilometers.

\section{Results}

What prima facie evidence is there for interdependent happiness in our data? In particular, is it the case that happier parents also have happier children? Table 3 shows a simple cross-tabulation of happiness for parents and children. Observations are pooled over five years. The original eleven point scale is collapsed into a trichotomy: 0-5, 6-7, 8-10 corresponding to the notions of below, average, and above average happiness. The table reveals a strong positive association between the happiness of adult children and the happiness of their parents. For example, only 23 percent of parents of adult children with below average happiness report an above average happiness themselves, compared to 44 percent of those parents with above average happy adult children. A formal Pearson chi-squared test rejects the independence hypothesis with $p$-value of zero. A similar result is obtained when the original eleven-point scale is used instead of the grouped categories.

Table 3 about here 
As mentioned before, the association in happiness of parents and children can reflect genetic and environmental factors as well as a true causal interdependence due to altruistic preferences. If happiness between parents and children were causally related, then one would expect to find that changes in happiness of parents are related to changes in happiness of children. Such an association is more convincing evidence for a causal relation, as it eliminates any potential confounding interference of time-invariant genetic and environmental factors. In Table 4 we show the distribution of year-to-year changes in a parent's happiness (decline / increase) conditional on year-to-year changes in the reported child happiness. The first two columns are for any decrease or increase, respectively, whereas the second two columns refer to large changes in a child's happiness, a decline or increase by a minimum of 3 points on the eleven point response scale.

Indeed, we find an association in first differences as well. For example, the relative frequency of an increase in happiness for parents is lowered by 7.1 percentage points if the child's happiness decreased by a minimum of 3 , compared to the case where the child's happiness increased by a minimum of 3 . In the "all changes" comparison, the corresponding association is reduced to a 4.6 percentage points difference. A Pearson chi-squared test indicates rejection of the independence assumption.

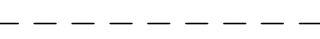

Table 4 about here

To summarize, the evidence is compatible with the notion that part of the association in happiness responses of parents and adult children is due to direct utility interdependence, or altruism. However, such a descriptive analysis cannot rule out that there are alternative explanations for interdependence. For a closer understanding of what these results tell us about altruism, we turn now to a more formal modeling approach. 


\subsection{Regression models of parental well-being}

A stochastic version of a linearized utility function of parents can be written as

$$
V_{p}=U_{p}+\eta U_{k}+u
$$

where $V_{p}$ is the overall utility function, $U_{p}=U\left(x_{p}\right)$ is the utility that parents derive from things other than their child's well-being, $U_{k}=U\left(x_{k}\right)$ is the child's utility, $u$ is a stochastic error term, and $\eta$ is the altruism parameter of interest. $x_{p}$ and $x_{k}$ include all factors that have been identified by the previous happiness literature as determinants of individual well-being. In traditional microeconomic utility models, as exemplified by Becker (1981), this would be primarily own consumption. The subjective well-being approach is broader, however, and $x$ therefore includes many other factors, such as marital status, health, and employment, besides income and consumption.

The important assumption captured by (1), apart from linearity, is the absence of paternalistic preferences. By this we mean that $x_{k}$ enters the parents' overall utility not directly, but only by way of mediation through the child's utility $U\left(x_{k}\right)$. This assumption may not be very plausible, depending on the variable $x_{k}$ we have in mind. We can easily think of some factors that make the child happy but the parent unhappy (such as perhaps an extramarital affair of the son or daughter). For other variables (such as age) the exclusion restriction of no direct effect may be more reasonable. Of course, the presence of paternalistic preferences does not mean that a parent cannot have altruistic preferences at the same time. It only makes its measurement from survey data harder, as it generates endogeneity in model (1), through correlation between $U_{k}$ and $u$. We return to this issue later.

Finally, the model does not say anything about more complex patterns of happiness interdependence, such as altruism of children towards their parents, or altruism between spouses. With altruism among spouses a third term, $V_{s}$, should be included. An increase in child happiness increases $V_{p}$ directly, through $\eta$, and indirectly, through its effect on $V_{s}$. (1) should then be interpreted as a partial reduced form, measuring the overall effect. 


\subsection{Pooled data regressions}

Happiness equations are often estimated using the ordered probit or the ordered logit model. However, as pointed out by van Praag and Ferrer-i-Carbonell (2004), such models imply an implicit cardinalization as well. While linear regression models do not allow to draw inference on single outcome probabilities (such as the probability of scoring an 8 or above on a 0-10 response scale), trade-off ratios can be computed, and there is widespread evidence (explored among others in Ferrer-i-Carbonell and Frijters, 2004) that these are quite robust to the choice of model. We use here the linear model approach, since it makes the required extensions to panel data and instrumental variable methods much more transparent.

First, let us consider the simplest model where $x_{p}$ and $x_{k}$ are independent and there are no paternalistic preferences. For this case, we can rewrite the utility function (1) as

$$
V_{p}=\eta U_{k}+v
$$

where $v=U_{p}+u$ and $\eta=\operatorname{Cov}\left(V_{p}, U_{k}\right) / \operatorname{Var}\left(U_{k}\right)$. Hence, a valid estimator of the altruism coefficient can be obtained from a simple bivariate regression of $V_{p}$ on $U_{k}$ using pooled data. From the first column of Table 5, we find that the estimated altruism parameter is $\hat{\eta}=0.25$. Since the standard deviations of parents' and children's happiness are 1.8 and 1.6, respectively, this parameter corresponds to a correlation of 0.21 . The correlation is highly significant.

The required assumption that $x_{p}$ and $x_{k}$ are unrelated is not very plausible. For example, it is known that intergenerational mobility in education and income is limited (for Germany, see e.g. Dustmann, 2004, and Lillard, 2001). Therefore, children of parents with above average income tend to have above average income themselves. Moreover, the education-health gradient means that healthier parents have healthier children. As a consequence, $x_{p}$ and $x_{k}$ are likely correlated, and the least squares regression coefficient from estimating (1) could be upward biased.

An obvious remedy to this problem is to assume that $U_{p}$ is a linear function of $x_{p}$, to include the parents' control variables $x_{p}$ in (1), and to estimate $\eta$ from the regression of $V_{p}$ on $U_{k}$ and $x_{p}$ :

$$
V_{p}=\alpha+x_{p}^{\prime} \beta+\eta U_{k}+u
$$


The results for such a regression are shown in the second column of Table 5. Controlling for other socio-economic factors, and thereby accounting for the correlation in consumption, endowments and preferences between parents and children, leads to a slightly reduced estimate of $\hat{\eta}=0.17$. The other aspects of model (2) mostly corroborate previous results for well-being equations known from the literature: health, unemployment, income, household size and house ownership enter in a statistically significant way (see for example Clark and Oswald, 1994, and Shields and Price, 2005, for typical wellbeing estimates). East Germans have a lower happiness, ceteris paribus, than West Germans (see also Frijters et al., 2004).

In principle, a positive relationship between a child's happiness and that of its parents may also be due to joy of giving. If parents derive direct happiness from making a transfer to their child, regardless of the consequences of the transfer for the child's utility, then such joy of giving will erroneously be interpreted as altruism. Thus, we included an indicator variable for the presence of monetary transfers over the course of the previous year. In principle, therefore, the joy of giving motive and the altruism motive can be estimated and tested separately. However, the coefficient on transfers is small and not statistically significant, and we thus find no evidence for a joy of giving motive.

The altruism parameter can be interpreted in terms of equivalent income variation. In the linear specification, this is simply the scaled ratio of two coefficients. Specifically, since income enters in logs, the effect is proportional: a doubling of income (an increase by $\ln 2=0.69 \log$ points) is predicted to increase the linear index ceteris paribus by 0.43 ; the change in happiness associated with a one point increase in a child's happiness is 0.17 , or about $40 \%$ of that associated with a doubling in income. This is a substantial amount.

Table 5 about here 
A simple extension of model (2) can account for paternalistic preferences. Re-write the model as

$$
V_{p}=\alpha+\eta U_{k}+x_{p}^{\prime} \beta+x_{k}^{\prime} \gamma+u
$$

Here, $\gamma$ measures the direct effect of the child's well-being determinants on parental happiness, ceteris paribus, for given child well-being, i.e., netting out the effect of "sympathy". The altruism parameter $\eta$ is then identified through residual variation in $U_{k}$ that is unrelated to the observed child characteristics $x_{k}$. The absence of paternalistic preferences can be tested via the restriction $H_{0}: \gamma=0$.

The third column of Table 5 shows the results for the augmented regression model (3). The coefficients and standard errors pertaining to child variables are printed in italics. Most of these coefficients are insignificant at conventional levels. For example, according to our estimates, neither health, marital status, nor employment status have a direct effect on parental happiness, for a given child happiness. Indeed, we cannot reject the joint hypothesis of no paternalistic preferences (the $p$-value of the $F$-test is $11.7 \%)$. On the other hand, the altruism parameter is almost unchanged, relative to the model without direct inclusion of the child variables. The evidence lends support for the simpler model (2), where parent-child interdependence is entirely captured by direct utility interdependence. This conclusion rests on the assumption that parents' utility does not depend on residual variation in $U_{k}$. If it does, $U_{k}$ and $u$ are correlated, and model (3) does not provide an unbiased estimator of $\eta$.

\subsection{Panel methods}

A panel data approach potentially can offer substantial improvement over the previous estimates. Essentially, there are two major issues so far: consumption and other happiness generating factors are transmitted from child to parent. Failure to fully control for the heterogeneity of these factors among parents would induce bias due to correlated unobservables. Similarly, failure to control for happiness generating factors among children would lead to endogeneity if parents have paternalistic preferences. Panel data can eliminate the endogeneity problem caused by such unobservables provided they are time invariant. In addition, fixed effects models will difference out genetic (and thus heritable) differences 
in one's attitude to happiness. For instance, "optimists" tend to report higher well-being levels (for a given $x$ ) than "pessimists", generating spurious positive correlation between parents' and children's well-being if left unaccounted for. The estimated model in this case is

$$
V_{p}=\alpha_{i}+x_{p}^{\prime} \beta+\eta U_{k}+u
$$

where $\alpha_{i}$ is the individual specific fixed effect. Model (4) is a fixed effects version of model (2) rather than model (3), based on the previous evidence that we cannot reject the absence of paternalism. The results for this model are shown in the fourth column of Table 5. From a statistical point of view - based on a Breusch Pagan test and a Hausman test respectively - the fixed effects estimator is clearly preferred over pooled OLS or a random effect GLS estimator, as the assumption of exogeneity of time-invariant individual effects is rejected.

Including fixed effects reduces the estimated altruism coefficient - the point estimate for $\eta$ is 0.041 - suggesting that correlation in time invariant unobservables (consumption, paternalism or personality) has some role to play. However, the coefficient is still significantly greater than zero, and the estimated income coefficient is also diminished, so that the trade-off ratio remains substantial. For example, a one standard deviation increase in the child's happiness is just offset by a 20 percent increase in household income.

\subsection{Instrumental variable estimation}

We finally re-estimated the model using instrumental variables. These estimates should be seen as robustness checks rather than genuine attempts of identifying causal effects, as the set of available instruments has a number of serious shortcomings. In principle, the within panel estimator of model (4) is consistent as long as all potential sources of endogeneity are time-invariant. Hence, there remains a problem if parents and children face correlated temporary shocks to their happiness. Two sources for such correlated shocks have already been discussed, namely correlated unobserved consumption

components and paternalistic preferences over unobserved determinants of child happiness. A third 
source for temporal variation, not considered so far, is simultaneity. If children have altruistic preferences with regard to their parents, we obtain a simultaneous equations system with two equations

$$
\begin{aligned}
& V_{p}=\alpha_{i, p}+x_{p}^{\prime} \beta_{p}+\eta_{p} V_{k}+v_{p} \\
& V_{k}=\alpha_{i, k}+x_{k}^{\prime} \beta_{k}+\eta_{k} V_{p}+v_{k}
\end{aligned}
$$

Here, the first equation refers to the parents' utility, with endogenous variable $V_{p}$, explanatory variables $x_{p}$ and $V_{k}$, and stochastic error term $u_{p}$. The second equation refers to the child's utility, with endogenous variable $V_{k}$, explanatory variables $x_{k}$ and $U_{p}$, and stochastic error term $v_{k}$. Single equation estimation of the first equation by ordinary least squares is unbiased if $V_{k}$ and $v_{p}$ are uncorrelated. There are two circumstances when this assumption fails: either the two temporary error terms $v_{p}$ and $v_{k}$ are correlated; or $\eta_{k} \neq 0$; or both. Suppose that $\sigma_{p k}=0$. Then a simple test of the absence of altruism is available if we assume that the altruism parameter is "mutual" and identical, since the ordinary least squares estimator is consistent under $H_{0}: \eta_{p}=\eta_{k}=0$. The practical importance of this result is limited, as there are many reasons to think that $\sigma_{p k} \neq 0$.

With endogeneity, estimation of the structural parameter $\eta_{p}$ can be based on instrumental variables. We use two types of instruments. First, if we believe in the absence of paternalistic preferences regarding specific observables (which does not rule out paternalistic preferences per se as long as they are limited to unobservables) - as exemplified by the system of equations (5) - then the implied exclusion from the first structural equation makes all variables in $x_{k}$ candidate instruments. In our model, there are 11 such variables (age and age squared, good health, married, divorced, years of schooling, unemployed, own children, house ownership, log household income, log household size; all measured for children). Second, a 12th instrument is based on the child's prediction of its "happiness in five years from now". While this variable may be a good instrument for measurement error, it likely fails to provide a source of genuinely independent variation, in particular as future happiness is very closely correlated with current happiness, so that endogeneity issues carry over. Re-estimating the model without this instrument did not make any sizeable difference. 
The instrumental variable results are shown in the last column of Table 5 . In the first stage regression, which is not shown here, health, employment and income have strong explanatory power. The instruments are highly significant as a group, with an $F$-statistic of 212 ( $p$-value $=0.000)$. Since there are more instruments than endogenous variables, we can test for the overidentifying restrictions. The $F$-statistic for this test has a $p$-value of 0.382 . Thus, we fail to reject the overidentifying restrictions: if one of the instruments is valid, then we don't reject that the others are so, too. This does of course not prove that the instruments are valid. We have discussed the substantive limitations of the available instruments earlier on, suggesting serious caveats to the interpretation of the results.

Still, we find it reassuring that the IV estimates fall within the range of estimates obtained from the previous estimation methods. The estimate of $\eta_{p}$ in the instrumented fixed effects model is 0.084 , an increase relative to the non-instrumented fixed effects model by a factor of about two. The direction of change suggests the presence of a negative correlation between the two idiosyncratic error terms $v_{p}$ and $v_{k}$. One possible explanation would be that the correlation is driven by paternalistic preferences over unobservables. For example, the parents may dislike a new boyfriend, or the fact that their child starts taking drugs, while these things increase the happiness of the child. An increase in the estimated coefficient after instrumenting can also be accounted for by measurement error, which is commonly exacerbated by taking within differences and which leads to attenuation bias.

The estimated income trade-off ratio in this model is 0.29 which is very similar to the trade-off ratio of 0.28 found in the pooled model (2). Thus, a one standard deviation increase in child happiness is just offset by an increase in log income of 0.45 .

\subsection{Further robustness checks}

We conducted some sub-sample checks to explore the robustness of the main association. Results are shown in Table 6 (we report only the estimated $\eta$ coefficients; all models include the same regressors as those used in Table 5). In a first split, we estimate separate models for mothers and fathers. The results are very similar. There is no clear indication that the altruism parameter is different for mothers 
than for fathers.

Table 6 about here

Second, we assess the sensitivity of the results to averaging over multiple child observations by restricting the sample to parents with one child only, or by matching parents with their oldest child only. Results show that averaging is inconsequential. The results are very similar in the full sample, the only child sample, and the oldest child sample.

A third comparison is between children who live in the same county and parent-child pairs where the distance between the two households is least 50 kilometers. One might conjecture that the estimated altruism parameter is greater for children living in the same county. First, parents might see these children more often, providing better information on their happiness. Second, part of the correlation might be spurious, because living nearby exposes parents and children to the same regional shocks (for example labor market conditions). This effect will be less pronounced for more distant children. Finally, distance may also be an endogenous choice by children, and it is conceivable that it increases with decreasing happiness interdependence.

The conjecture of a negative relationship between interdependence and distance is not supported by the evidence. Indeed, the sizes of the coefficients in the "distant sample" and in the "nearby" sample are quite similar. In the distant sample, the fixed effects IV estimates are insignificant, but this can be largely attributed to the smaller sample size of that group. Moreover, it can be shown that the point estimate for the income trade-off ratio in the instrumented model in the distant sample is even at the higher end, as the estimated income coefficient is only 0.11. A point-increase in child happiness therefore corresponds to a $0.061 / 0.11=0.55$ increase in log household income.

Finally, we compare children who moved out recently with those who moved out at least 10 years ago. Again, one would expect that the estimated altruism parameter is greater for those children who 
just moved out of their home, for instance, because parents can be expected to have better information on the happiness of these children compared to those who left home earlier. We find some larger estimates for the recent sample. However, the results for the subsample of children who left home at least 10 years ago remain statistically significant and very similar to the overall results. While the point estimates for $\eta$ thus vary somewhat depending on subsample and specification, there is nevertheless a clear message in these results. The "coefficient of effective sympathy" is an important component of well-being, happiness appears to be interdependent.

\section{Conclusions}

Modeling happiness interdependence is a promising new area of research that allows for a quantification and direct testing of the altruism hypothesis. Using data from the German Socio-Economic Panel for the years 2000-2004, we constructed a dataset on extended families, comprised of a parent household and related households of adult children. We estimated the association between parent and child happiness using a number of specifications, including fixed effects models with and without instrumental variables, and found robust evidence for a statistically significant positive association.

Since parents' happiness is positively related to the happiness of their children, parents potentially have incentives to transfer income to their children. We can invert the income compensation ratio to obtain the increase in child happiness required for compensating for a given reduction in income. Based on our estimates, these range between 2.2 and 5. For a one percent increase in own income, child happiness must then increase by between 0.02 and 0.05 for full compensation. For larger responses, transfers will increase parents' happiness. Assuming that children respond in the same way to income as their parents, such large transfer induced happiness increases will only materialize if children have much lower incomes, for only then is it possible that a one percent transfer of parental income can increase child income by several percent.

Our approach to, and finding of, interdependent happiness have implications beyond the specific issue 
of altruism within the extended family. More broadly, such interdependence implies that happiness has an important collective dimension that was ignored by much of prior research. As also found in a current paper on happiness among friends (Fowler and Christakis, 2008), happiness seems to be "contagious". Increasing the happiness of one person is associated with happiness spillovers among a pool of related persons. This is an important insight when thinking about the welfare implications of policies. In particular, contagion implies that the social benefit of an intervention that makes one person happier is likely to exceed the private benefit by far.

The analysis in this paper is a first step towards gaining an understanding of the collective dimension of happiness, and interdependence as a proximate mechanism for altruism. There are at least two promising avenues for further research. One is a more detailed exploration of individual heterogeneity in the "sympathy" parameter. The other is a confirmation of the nature of causality, based on better instruments that capture genuinely exogenous variation in child happiness. Such an analysis needs to confront the issue that the relationships people maintain, be it within the extended family or outside with friends, may be partly self-selected: at what time children move out, how far they move and what contact they keep, is influenced by both parents and children attitudes and may reflect in part the degree of happiness interdependence between the two. 


\section{References}

Altonji, J.G., F. Hayashi and L.J. Kotlikoff (1992) Is the extended family altruistically linked? Direct tests using micro data, American Economic Review 82, 1177-1198.

Andreoni, J. (1990) Impure Altruism and Donations to Public Goods: A Theory of Warm-Glow Giving, Economic Journal 100, 464-477.

Becker, G.S. (1981) Altruism in the Family and Selfishness in the Market Place, Economica 48, 1-15.

Becker, G.S. (1991)A Treatise on the Family. 2nd ed., Cambridge, Mass.: Harvard University Press.

Clark, A.E. and A.J. Oswald (1994) Unhappiness and Unemployment, Economic Journal 104, 648-659.

Clark, A.E. and A.J. Oswald (1996) Satisfaction and Comparison Income, Journal of Public Economics $61,359-381$.

Clark, A.E., Y. Georgellis and P. Sanfey (1998) Job Satisfaction, wage changes and quits: evidence from Germany, Research in Labour Economics, 17, 95- 121.

Clark, A.E., P. Frijters and M.H. Shields (2008a) Relative Income, Happiness and Utility: An Explanation for the Easterlin Paradox and Other Puzzle, Journal of Economic Literature 46, 95-144.

Clark, A., E. Diener, Y. Georgellis and R. Lucas (2008b) Lags and leads in life satisfaction: A test of the baseline hypothesis, Economic Journal 118, F222-F443.

Diener, E. (1984) Subjective well-being, Psychological Bulletin 95, 542-575.

Diener, E., R.A. Emmons, R.J. Larsen, and S.Griffin (1985) The Satisfaction With Life Scale, Journal of Personality Assessment 49, 71-75.

Di Tella, R. and MacCulloch, R. (2006). Some uses of happiness data in economics, Journal of Economic Perspectives 20, 25-46. 
Dustmann, C. (2004) Parental background, secondary school track, and wages, Oxford Economic Papers 56, 209-230.

Edgeworth, F.Y. (1881), Mathematical Psychics, Reprinted in: Peter Newman (ed.) (2003) F.Y. Edgeworth: Mathematical Psychics and Further Papers on Political Economy, Oxford University Press.

Fehr, E. and U. Fischbacher (2003) The nature of human altruism, Nature 425, 785-791.

Ferrer-i-Carbonel, A. and P. Frijters (2004) The effect of metholodogy on the determinants of happiness, Economic Journal 114, 641-659.

Fowler, J.H. and N.A. Christakis (2008) Dynamic spread of happiness in a large social network: longitudinal analysis over 20 years in the Framingham Heart Study, British Medical Journal doi:10.1136/bmj.a2338.

Frey, B. S. and A. Stutzer (2002) What can economists learn from happiness research? Journal of Economic Literature, 40, 402-435.

Frijters, P., J.P. Haisken-DeNew and M.A. Shields (2004) Money does matter! Evidence from increasing real income and life satisfaction in East Germany following reunification, American Economic Review 94, 730 - 740 .

Laferrére, A. and F.C. Wolff (2006) Microeconomic models of family transfers. Chapter 13 in: S.C. Kolm and J. Mercier Ythier (eds.): Handbook on the Economics of Giving, Reciprocity and Altruism, North-Holland: Elsevier, 890-971.

Layard, R. (2005) Happiness: Lessons from a New Science, Penguin Books, London.

Lillard, D.R. (2001) Earnings and income mobility, Vierteljahreshefte zur Wirtschaftsforschung 70 (1), $51-58$. 
Powdthavee, N. (2009) I can't smile without you: Spousal correlation in life satisfaction, Journal of Economic Psychology 30, 675-689.

Ribar, D.C. and M.O. Wilhelm (2002) Altruistic and Joy-of-Giving Motivations in Charitable Behavior, Journal of Political Economy 110, 425-457.

Shields, M.A. and S.W. Price (2005) Exploring the economic and social determinants of psychological well-being and perceived social support in England Journal of the Royal Statistical Society: Series $A, 168,513-537$.

Smith, A. (1790) The Theory of Moral Sentiments A. Millar. Library of Economics and Liberty. 25 September 2006. ¡http://www.econlib.org/LIBRARY/Smith/smMS1.htmli.

van Praag, B. and A. Ferrer-i-Carbonell (2004) Happiness Quantified - A Satisfaction Calculus Approach, Oxford University Press.

Veenhoven, R. (1997) The utility of happiness, Social Indicators Research 20, 333-354.

Wagner, G. G., R. V. Burkhauser and F. Behringer (1993) The English Language Public Use File of the German Socio-Economic Panel, Journal of Human Resources, 28, 429- 433.

Winkelmann, R. (2005) Subjective well-being and the family: results from an ordered probit model with multiple random effects, Empirical Economics 30, 749-761. 
Table 1: Structure of the data set 2002

\begin{tabular}{|c|c|c|c|c|c|c|}
\hline \multirow{2}{*}{$\begin{array}{l}\text { Children not living in } \\
\text { parents' household }\end{array}$} & \multicolumn{2}{|c|}{ Number of parents } & \multirow{2}{*}{$\begin{array}{l}\text { Mothers } \\
\text { Frequency }\end{array}$} & \multirow{2}{*}{$\begin{array}{c}\text { Fathers } \\
\text { Frequency }\end{array}$} & \multirow{2}{*}{$\begin{array}{c}\text { Number of } \\
\text { observations } \\
\text { Frequency }\end{array}$} & \multirow[b]{2}{*}{ Percent } \\
\hline & Frequency & Percent & & & & \\
\hline One & 1,317 & 75.3 & 708 & 609 & 1,317 & 58.0 \\
\hline Two & 363 & 20.7 & 199 & 164 & 726 & 32.2 \\
\hline Three & 61 & 3.5 & 33 & 28 & 183 & 8.1 \\
\hline Four & 7 & 0.4 & 4 & 3 & 28 & 1.2 \\
\hline Five & 2 & 0.1 & 1 & 1 & 10 & 0.4 \\
\hline Total & 1,750 & 100 & 945 & 805 & 2,264 & 100 \\
\hline $\begin{array}{l}\text { Parents in two-parent } \\
\text { households }\end{array}$ & 1,454 & 83.1 & - & - & - & - \\
\hline
\end{tabular}

Source: GSOEP 2002. 
Table 2: Descriptive Statistics

\begin{tabular}{lcccc}
\hline \hline & \multicolumn{2}{c}{ Parents } & \multicolumn{2}{c}{ Children } \\
Variable & mean & std.dev. & mean & std.dev. \\
\hline Happiness & 6.57 & 1.80 & 7.06 & 1.59 \\
Female & 0.54 & 0.50 & 0.51 & 0.50 \\
Age & 57.4 & 8.7 & 30.7 & 6.1 \\
Good health & 0.31 & 0.46 & 0.70 & 0.46 \\
Married & 0.82 & 0.38 & 0.46 & 0.50 \\
Years of schooling & 11.2 & 2.4 & 12.3 & 2.5 \\
Unemployed & 0.08 & 0.28 & 0.07 & 0.25 \\
Retired & 0.33 & 0.47 & & \\
House ownership & 0.56 & 0.50 & 0.26 & 0.44 \\
Log household income & 8.29 & 0.52 & 8.16 & 0.56 \\
Log household size & 0.80 & 0.39 & 0.77 & 0.54 \\
Distance (in km) & 49.3 & 112.1 & & \\
Same district & 0.64 & 0.48 & & \\
Number of children & 1.97 & 1.19 & & \\
Age at leaving home & & & 23.3 & 4.4 \\
Year 2000 & 0.18 & 0.39 & 0.18 & 0.39 \\
Year 2001 & 0.19 & 0.39 & 0.19 & 0.39 \\
Year 2002 & 0.20 & 0.40 & 0.20 & 0.40 \\
Year 2003 & 0.21 & 0.41 & 0.21 & 0.41 \\
Year 2004 & 0.22 & 0.41 & 0.22 & 0.41 \\
\hline Observations & $8630^{a}$ & & $6520^{b}$ \\
\hline \hline
\end{tabular}

Source: GSOEP 2000-2004.

${ }^{a}$ Excludes multiple person-year observations for parents with several children.

${ }^{b}$ Excludes multiple person-year observations for children with two parents. 
Table 3: Happiness responses of parents and children (in percent, $n=8630$ )

\begin{tabular}{lcccc}
\hline \hline \multirow{5}{*}{$\begin{array}{l}\text { Happiness } \\
\text { of parent }\end{array}$} & $0-5$ & $6-7$ & $8-10$ & total \\
\cline { 2 - 5 } & & & & \\
$0-5$ & 40.0 & 27.9 & 20.1 & 26.6 \\
$6-7$ & 36.9 & 40.7 & 36.3 & 38.3 \\
$8-10$ & 23.1 & 31.4 & 43.6 & 35.1 \\
& & & & \\
total & 100.0 & 100.0 & 100.0 & 100.0 \\
\hline \hline
\end{tabular}

Source: GSOEP 2000-2004.

Table 4: Changes in happiness responses of parents between $t-1$ and $t$, conditional on changes for children (in percent)

\begin{tabular}{lcccc}
\hline \hline & \multicolumn{3}{c}{ Change in happiness of child } \\
\hline Change in happiness & \multicolumn{2}{c}{ any change } & \multicolumn{2}{c}{ large change } \\
of parent & $\leq-1$ & $\geq+1$ & $\leq-3$ & $\geq+3$ \\
\cline { 2 - 5 } & 55.5 & 50.9 & 59.6 & 52.5 \\
decrease & 45.5 & 49.1 & 40.4 & 47.5 \\
increase & & & & \\
& 100.0 & 100.0 & 100.0 & 100.0 \\
total & 1173 & 954 & 166 & 143 \\
observations & 0.036 & 0.204 \\
$P$-val. chi-squared & \multicolumn{4}{c}{. }
\end{tabular}

Source: GSOEP 2000-2004. 
Table 5: Regression results for parent's happiness, $N=8630$

\begin{tabular}{|c|c|c|c|c|c|c|}
\hline & (1) & $(2)$ & & & $(4)$ & $(5)$ \\
\hline & \multirow[b]{2}{*}{$\begin{array}{c}0.250^{* *} \\
(0.019)\end{array}$} & & parent & child & \multirow[b]{2}{*}{$\begin{array}{l}0.041^{*} \\
(0.020)\end{array}$} & \multirow[b]{2}{*}{$\begin{array}{c}0.084^{* *} \\
(0.025)\end{array}$} \\
\hline Happiness of child $(\eta)$ & & $\begin{array}{c}0.168^{* *} \\
(0.017)\end{array}$ & $\begin{array}{c}0.168^{* *} \\
(0.018)\end{array}$ & & & \\
\hline Transfers (yes/no) & & $\begin{array}{c}0.082 \\
(0.063)\end{array}$ & $\begin{array}{c}0.076 \\
(0.064)\end{array}$ & & $\begin{array}{c}0.007 \\
(0.066)\end{array}$ & $\begin{array}{c}0.011 \\
(0.051)\end{array}$ \\
\hline East Germany & & $\begin{array}{c}-0.310^{* *} \\
(0.063)\end{array}$ & $\begin{array}{c}-0.345^{* *} \\
(0.064)\end{array}$ & & - & - \\
\hline Good health & & $\begin{array}{c}1.088^{* *} \\
(0.047)\end{array}$ & $\begin{array}{c}1.079^{* *} \\
(0.046)\end{array}$ & $\begin{array}{l}0.048 \\
(0.064)\end{array}$ & $\begin{array}{c}0.392^{* *} \\
(0.052)\end{array}$ & $\begin{array}{c}0.393^{* *} \\
(0.043)\end{array}$ \\
\hline Unemployed & & $\begin{array}{c}-0.628^{* *} \\
(0.098)\end{array}$ & $\begin{array}{c}-0.617^{* *} \\
(0.098)\end{array}$ & $\begin{array}{l}0.066 \\
(0.088)\end{array}$ & $\begin{array}{c}-0.378^{* *} \\
(0.118)\end{array}$ & $\begin{array}{c}-0.383^{* *} \\
(0.076)\end{array}$ \\
\hline Retired & & $\begin{array}{l}-0.114 \\
(0.079)\end{array}$ & $\begin{array}{l}-0.111 \\
(0.078)\end{array}$ & & $\begin{array}{c}0.067 \\
(0.083)\end{array}$ & $\begin{array}{c}0.067 \\
(0.069)\end{array}$ \\
\hline House ownership & & $\begin{array}{c}0.275^{* *} \\
(0.059)\end{array}$ & $\begin{array}{c}0.251^{* *} \\
(0.060)\end{array}$ & $\begin{array}{c}0.131+ \\
(0.071)\end{array}$ & $\begin{array}{l}-0.040 \\
(0.180)\end{array}$ & $\begin{array}{l}-0.041 \\
(0.112)\end{array}$ \\
\hline Log household income & & $\begin{array}{c}0.624^{* *} \\
(0.067)\end{array}$ & $\begin{array}{c}0.627^{* *} \\
(0.068)\end{array}$ & $\begin{array}{r}-0.162^{*} \\
(0.069)\end{array}$ & $\begin{array}{c}0.301^{* *} \\
(0.110)\end{array}$ & $\begin{array}{c}0.291^{* *} \\
(0.072)\end{array}$ \\
\hline Log household size & & $\begin{array}{c}-0.284^{*} \\
(0.115)\end{array}$ & $\begin{array}{c}-0.281^{* *} \\
(0.115)\end{array}$ & $\begin{array}{l}0.105 \\
(0.105)\end{array}$ & $\begin{array}{c}0.204 \\
(0.177)\end{array}$ & $\begin{array}{c}0.209 \\
(0.132)\end{array}$ \\
\hline Distance & & $\begin{array}{c}-0.065^{*} \\
(0.029)\end{array}$ & $\begin{array}{c}-0.060^{*} \\
(0.029)\end{array}$ & & $\begin{array}{l}-0.069 \\
(0.072)\end{array}$ & $\begin{array}{l}-0.069 \\
(0.047)\end{array}$ \\
\hline Same county & & $\begin{array}{c}-0.036 \\
(0.073)\end{array}$ & $\begin{array}{l}-0.024 \\
(0.074)\end{array}$ & & $\begin{array}{l}-0.113 \\
(0.132)\end{array}$ & $\begin{array}{c}-0.114 \\
(0.099)\end{array}$ \\
\hline Fixed effects & No & No & & & Yes & Yes \\
\hline Instruments & No & No & & & No & Yes \\
\hline
\end{tabular}

Notes:

Analysis based on data from the German Socio-economic Panel 2000-2004.

Standard errors in parentheses; in models (1) to (3) they have been adjusted for clustering at the individual level.

The $x_{k}$ column in model (3) in italics refers to the child characteristics.

+ significant at 10 percent; * significant at 5 percent; ** significant at 1 percent

All models include a constant and, except for model (1), four dummies indicating the survey year, a polynomial in age, gender, marital status and years of schooling. 
Table 6: Results for Different Samples

\begin{tabular}{|c|c|c|c|c|}
\hline & (1) & $(2)$ & $(3)$ & $(4)$ \\
\hline \multicolumn{5}{|l|}{ Women $(n=4675)$} \\
\hline \multirow[t]{2}{*}{ Happiness of child } & $0.266^{* *}$ & $0.183^{* *}$ & 0.038 & $0.077^{*}$ \\
\hline & $(0.026)$ & $(0.024)$ & $(0.026)$ & $(0.035)$ \\
\hline \multicolumn{5}{|l|}{ Men $(n=3955)$} \\
\hline \multirow[t]{2}{*}{ Happiness of child } & $0.230^{* *}$ & $0.150^{* *}$ & $0.043+$ & $0.098^{* *}$ \\
\hline & $(0.029)$ & $(0.026)$ & $(0.025)$ & $(0.036)$ \\
\hline \multicolumn{5}{|c|}{ Only 1 child living outside the parents household $(n=6524)$} \\
\hline \multirow[t]{2}{*}{ Happiness of child } & $0.226^{* *}$ & $0.153^{* *}$ & 0.028 & $0.081^{* *}$ \\
\hline & $(0.025)$ & $(0.022)$ & $(0.024)$ & $(0.030)$ \\
\hline \multicolumn{5}{|l|}{ First child $(n=7646)$} \\
\hline \multirow[t]{2}{*}{ Happiness of child } & $0.216^{* *}$ & $0.140^{* *}$ & 0.024 & $0.070^{* *}$ \\
\hline & $(0.023)$ & $(0.020)$ & $(0.021)$ & $(0.026)$ \\
\hline \multicolumn{5}{|c|}{ Living in same county $(n=5301)$} \\
\hline \multirow[t]{2}{*}{ Happiness of child } & $0.231^{* *}$ & $0.160 * *$ & 0.033 & $0.076^{* *}$ \\
\hline & $(0.028)$ & $(0.025)$ & $(0.021)$ & $(0.032)$ \\
\hline \multicolumn{5}{|c|}{ Living at least $50 \mathrm{~km}$ apart $(n=1919)$} \\
\hline \multirow[t]{2}{*}{ Happiness of child } & $0.222^{* *}$ & $0.160^{* *}$ & -0.013 & 0.061 \\
\hline & $(0.058)$ & $(0.050)$ & $(0.032)$ & $(0.058)$ \\
\hline \multicolumn{5}{|c|}{ Moved out during the last year $(n=1073)$} \\
\hline \multirow[t]{2}{*}{ Happiness of child } & $0.301^{* *}$ & $0.192^{* *}$ & $0.164^{*}$ & 0.183 \\
\hline & $((0.049)$ & $(0.041)$ & $(0.071)$ & $(0.114)$ \\
\hline \multicolumn{5}{|c|}{ Moved out more than 10 years ago $(n=2968)$} \\
\hline \multirow[t]{2}{*}{ Happiness of child } & $0.210^{* *}$ & $0.167 * *$ & 0.045 & $0.071+$ \\
\hline & $(0.038)$ & $(0.034)$ & $(0.031)$ & $(0.041)$ \\
\hline Controls & no & yes & yes & yes \\
\hline Fixed Effects & no & no & yes & yes \\
\hline Instruments & no & no & no & yes \\
\hline
\end{tabular}

Notes:

see Table 5;

only the estimated altruism parameters $\hat{\eta}$, together with standard error in parentheses, are shown here. 